\title{
CRONOMOSAICOS: METÁFORAS \\ ESPACIALES DEL TIEMPO EN LA NOVELA HIPERMEDIA TOC, DE STEVE TOMASULA
}

Juan Alberto Conde $e^{(a)}$

CHRONOMOSAICS: SPATIAL METAPHORS OF TIME IN

TOC HYPERMEDIA NOVEL BY STEVE TOMASULA

CHRONOMOSAICS: METÁFORAS ESPACIAIS DO TEMPO NO

LIVRO HIPERMÍDIA TOC, DE STEVE TOMASULA

Fecha de recepción: 11 de junio del 2018

Fecha de aprobación: 21 de diciembre del 2018

Disponible en línea: 20 de febrero del 2019

\section{Sugerencia de citación:}

Conde, J. A. (2019). Cronomosaicos: metáforas espaciales del tiempo en la novela hipermedia TOC, de Steve Tomasula. Razón Crítica, 6, 113-132, doi: 10.21789/25007807.1442

\section{(a) Juan Alberto Conde}

Comunicador social y Magíster en Filosofía de la Pontificia Universidad Javeriana

Doctor en Ciencias del lenguaje de la Univesite de Limoges

Profesor de la Facultad de Ciencias Sociales de la

Universidad de Bogotá Jorge Tadeo Lozano, Colombia

juan.conde@utadeo.edu.co 


\section{R E S U M E N}

En este artículo se hace un análisis de la novela interactiva Toc: A New Media Novel (2009), del escritor y artista norteamericano Steve Tomasula a partir de las metáforas conceptuales que propone en torno a la temporalidad. A partir de estos tropos temporales, se ofrece una reflexión en torno a las particularidades de la ficción interactiva, tanto en sus formas narrativas como en su relación con los soportes tecnológicos en los que se fundamenta. Así mismo, se propone un acercamiento a la manera en que la semántica cognitiva ha abordado la manera en que los seres humanos conceptualizamos el tiempo, tratando de extender sus análisis basados en el lenguaje verbal al ámbito de los medios audiovisuales interactivos.

PALABRAS CLAVE: narración interactiva, semántica cognitiva, metáfora conceptual, teoría de la integración conceptual, tiempo, тос, Steve Tomasula. 


\section{A B S T R A C T}

This article examines the interactive novel Toc: A New Media Novel (2009), by American writer and artist Steve Tomasula, based on the conceptual metaphors he proposes about temporality. Drawing from these temporal tropes, we present a reflection on the particularities of interactive fiction, both in its narrative forms and its connection with the technological supports it is build upon. Likewise, we propose an approach to the way in which cognitive semantics has addressed the way human beings conceptualize time, trying to expand their analysis from the verbal language to the realm of interactive audiovisual media.

KEY WORDS: Interactive narrative, cognitive semantics, conceptual metaphor, theory of conceptual integration, time, тос, Steve Tomasula.

\section{R E S U M O}

Neste artigo, é feita uma análise do romance interativo Toc: A New Media Novel (2009), do escritor e artista americano Steve Tomasula, baseado nas metáforas conceituais propostas por ele sobre a temporalidade. A partir desses tropos temporais, uma reflexão em torno das particularidades da ficção interativa é oferecida, tanto em suas formas narrativas quanto em sua relação com os suportes tecnológicos nos quais ela se baseia. Da mesma forma, propomos uma abordagem à maneira em que a semântica cognitiva abordou a forma dos seres humanos conceituarem o tempo, tentando estender sua análise baseada na linguagem verbal ao âmbito da mídia audiovisual interativa.

PALAVRAS-CHAVE: metáfora conceitual, narrativa interativa, semântica cognitiva, Steve Tomasula, tempo, teoria da integração conceitual, TOC. 
Nuestras formas de arte, incluyendo la literatura, cambian continuamente, en función de la manera como nos concebimos a nosotros mismos y como concebimos el mundo [...] Nos podemos plantear la misma cuestión acerca de los patrones que están siendo creados por el creciente poder de los computadores, el aumento en el número y tamaño de las bases de datos, de nuestras herramientas y de nuestras organizaciones sociales, tanto virtuales como físicas. Todos estos cambios incrementan la presión sobre las viejas formas de arte hasta que, finalmente, como dice Moretti, estas "ya no representen los aspectos más significativos de la realidad contemporánea" [...] La novela lineal parece no ajustarse, pero entonces, ¿qué forma lo hace? Mirando hacia atrás, creo que no capté correctamente la metáfora —yo estaba pensando en [las novelas] más como collages o mosaicos, en los cuales muchas piezas pequeñas se juntan para crear una imagen más grande, pero ahora puedo ver más claramente que hacia donde me estaba arrastrando era hacia la emulación de una forma de emergencia: una forma en la que muchas acciones pequeñas, todas creadas por sus propias razones, se juntan para crear patrones más amplios; luego estos patrones amplios se combinan con otros para crear patrones aún más grandes, y asi sucesivamente. 
Desde su propio título, la novela interactiva ToC de Steve Tomasula, publicada en su primera versión para PC en el 2009, es una compleja meditación sobre el tiempo. TOC, la mitad de la onomatopeya que en inglés representa el sonido de los relojes mecánicos, evoca a su otra mitad y crea en nuestros oídos una especie de ritmo incompleto, que nuestras interacciones deben completar. Pero la cuestión de la temporalidad afecta a la propia obra en su materialidad tecnológica en una paradoja inevitable: en un tiempo de caducidades programadas, el intento de esta novela por interpelar al presente, se va enfrentando a la fugacidad tecnológica, a la aceleración de sus transformaciones.

Así, una obra cuyo subtítulo rezaba: "una novela de los nuevos medios" (a new media novel) se convierte ahora, por lo menos en su primera versión, en una novela de un (ya casi) viejo medio: el computador de escritorio, que aunque se niega a extinguirse frente al auge de las tabletas, los teléfonos inteligentes y demás dispositivos portátiles, está sujeto a las actualizaciones de sistemas operativos cada vez más frecuentes, de manera que aquella primera versión de la novela digital de Tomasula ya no se puede instalar en muchos computadores de hoy en día. Kathi Inman Berens cuenta las dificultades insalvables que tuvo para hacerlo en su computador Apple, con una versión de ios que ya no era compatible con el software de TOC (Berens, 2015).

En mi caso, la primera vez que "leí" (o "audiovisualicé) ToC fue en el 2011, en un PC con sistema Windows, instalándola desde un DVD a la manera de un videojuego. En ese entonces, presenté una ponencia sobre la obra de Tomasula en el Festival de la imagen de Manizales, y resaltaba las ventajas que tenía esta forma de acceder a la novela:

TOC: A New Media Novel, se adquiere en el mercado en forma de DVD, en un estuche de cartón a la manera de una película en DVD o un CD de audio. Esta forma de distribución retrotrae la obra al universo enciclopédico del mundo editorial, y la aleja de otras obras hipermedia de distribución en línea: TOC es, al menos materialmente, un producto cerrado, con límites ontológicos y textuales claros. Todas sus conexiones son internas, su universo semiótico es autocontenido. Pero si esta decisión restringe la navegabilidad abierta de la obra, también permite que sus contenidos audiovisuales y sonoros tengan una resolución mejor que la mayoría de las novelas hipertextuales o la narrativa en línea, acercándola a una forma de cine interactivo: las películas se ven y se escuchan con nitidez y sin retrasos o esperas para cargarse, de modo 
que se transita de un video a una pantalla interactiva de manera fluida y versátil (Conde, 2011).

En esta nueva lectura, TOC sigue funcionando en las últimas versiones de Windows, aunque su resolución ya no parece tan alta: ahora su superficie de pantalla es mucho más pequeña, y queda suspendida sobre un fondo negro que ocupa el resto del espacio de visualización. No obstante, los habitantes del "ecosistema" Apple tuvieron otra forma de acceder a TOC, pues en el 2014 fue lanzada una versión de la novela como aplicación de iPad, aunque solo disponible en Estados Unidos. Aunque su funcionamiento en este nuevo soporte empieza a revelar su obsolescencia, Berens ha demostrado cómo la novela se sostiene en medio de esa fragilidad e interpela de forma poderosa la temporalidad de la tecnología:

TOC es una app para viajar en el tiempo: una "novela de los nuevos medios" que esquivó una muerte asegurada, una vez más, y que carga las huellas de su estancia en un antiguo sustrato mediático. La adaptación de la novela al iPad tiene éxito en sus propios términos, como un Thunderbird negro de 1964 en una autopista de cinco carriles rebasando montones de Smart Cars (Berens, 2015, p. 181) ${ }^{1}$.

Pero mientras su materialidad técnica envejece con dignidad, los retos conceptuales que propone no solo son vigentes, sino que atacan el corazón mismo de la concepción contemporánea del tiempo. Así mismo, la vida pública de la novela también recoge en su temporalidad las múltiples lecturas e interpretaciones a la que ha sido sujeta en los años transcurridos desde su publicación, convirtiéndose ya en todo un clásico de la literatura digital, con poco menos de diez años de existencia. Para N. Katherine Hayles, тос ejemplifica una transformación en las maneras en que los seres humanos experimentamos la temporalidad en entornos tecnológicos:

En un nuevo entorno, que cambia tan rápido que una generación puede constar de solo dos o tres años, la metastabilidad provisional

1 Inman-Berens demuestra cómo la remediación de toc en el iPad no deja de ser problemática: siendo una aplicación orientada originalmente a los desktops y su lógica del cursor y el ratón, la interfaz de la novela desaprovecha el potencial de los gestos táctiles de la tableta. Además, lo pesado de su código hizo imposible que la aplicación funcionara también para iPhone, y esto restringía el acceso a la novela por parte de un público más amplio. No obstante, los conceptos que baraja y las metáforas y narrativas que propone anticipan las nuevas formas de relato digital (Inman-Berens, 2015). 
de los objetos técnicos puede volverse aún menos estable, por lo que es más preciso hablar incluso de transformación continua que de metastabilidad. TOC anticipa esto al revelar la inestabilidad inherente de los regímenes temporales, las rupturas cataclísmicas que ocurren cuando las sociedades son arrancadas de un régimen y sumergidas en otro, y la incapacidad de las narraciones para crear cualquier régimen temporal que sea duradero y que abarque todo. Este aspecto, puede ser visto como un comentario sobre sus propias condiciones de posibilidad. La circularidad de una obra que produce y es producida por sus posibilidades estéticas puede ser un mejor criterio para juzgar su logro que las convenciones de la cultura impresa relativamente establecidas. [...] TOC está habitado por complejas temporalidades que se niegan a resolverse en secuencias definidas o a proporcionar límites definitivos entre los seres vivos y los objetos técnicos (Hayles, 2012, p. 143).

Es en ese sentido que propongo esta nueva visita al mundo donde los hermanos Cronos y Logos se debaten por el dominio de una isla que es la versión fractal de nuestro universo. Exploremos primero su narrativa.

\section{Los cronopaisajes de $T O C$}

La puerta de entrada a la novela es un epígrafe de San Agustín: "Entonces, ¿qué es el tiempo? Si nadie me lo pregunta, lo sé. Si se lo quiero explicar a alguien que me lo exige, no lo sé”.

En seguida, en una animación introductoria una voz en off describe un escenario paradójico: "Un mundo distante brilla desde el pasado de otro mundo que es simultáneamente nuestro futuro. ¿Es esta una onda en el tiempo? ¿O en la existencia?”.

Este narrador habla de Efemera, una reina que inventó una máquina diferencial que hizo posible medir el tiempo, llevando a su civilización al caos con este invento, por lo que tuvo que huir, dando a luz a gemelos llamados Logos y Cronos durante su huida. Efemera se estableció con su gente en una isla. Al crecer, sus hijos "[...] luchan sin cesar por la sucesión al trono de su madre”, pues no es claro cuál de los dos tiene el derecho: "[...] uno nació el viernes por la mañana. Una hora más tarde, después de cruzar a una nueva zona horaria, el segundo hijo nació el jueves por la noche. Aunque Chronos nació primero, Logos nació en una fecha anterior". 
Cronos y Logos se convierten así en los dos personajes principales de esta historia y dos formas complementarias y confrontadas de conceptualizar el tiempo. Después de esta animación, el lector/espectador/ usuario de TOC pasa a la primera pantalla de navegación, donde puede recoger (usando el cursor en la versión de PC) una piedra desde el lado derecho de la pantalla y arrastrarla a una de dos cajas o recipientes, correspondientes a los dos hermanos. Cronos está representado por el agua y Logos por la arena: dos variaciones visuales de dos de las principales formas materiales para medir el tiempo: la clepsidra y el reloj de arena.

La caja de Cronos activa una película animada que muestra imágenes de mecanismos de relojería, diagramas, caligrafía, osciladores, textos animados y otras representaciones gráficas ${ }^{2}$, mientras se narra en off con voz femenina la historia de una modelo de Vogue en una situación particular: su esposo sufrió un accidente y es mantenido vivo por medios artificiales, por lo que ella tiene que decidir entre desconectarlo y dejarlo descansar en paz, o que continúe con vida en ese estado. Por otro lado, ha descubierto que está embarazada, pero el padre de su hijo es su propio hermano, así que enfrenta otra decisión: si interrumpir su embarazo, resultado de un incesto o continuar con este. Esta narrativa nos enfrenta así a dos dilemas relativos al comienzo y al final de la vida. La película se puede ver en un formato pequeño, dentro de la campana de cristal que lo contiene en la pantalla de Cronos, o, si se hace clic sobre este, se despliega una versión de pantalla completa. En el primer caso, hay un dial que permite al usuario avanzar o retroceder a través de la línea de tiempo del video.

La opción de Logos ofrece un nivel más amplio de interactividad: en esta caja hay una imagen de un rollo de pianola que comienza a moverse, acompañada de música típica de este instrumento automático. Al pasarlo sobre el rollo, el cursor se convierte en una mira en forma de cruz, y el usuario puede hacer clic sobre las ranuras en movimiento del rollo: las

2 Alison Gibbons cuenta que esta película tiene como antecedente una pieza gráfica editorial:

[...] publicada en una revista de poesía de Nueva York llamada Literal Latté, fundada en 1994. Luego apareció en Black Ice en 1996 como un texto acompañado de imágenes y finalmente en el número 37 de la revista de arte Émigré. Así mismo, esta obra en papel formó parte de una exposición en el Center for the Book and Paper Arts de Chicago, en forma de una cinta de Moebius que colgaba del techo, y que también incluía la lectura de textos por parte de Tomasula y su esposa, María Tomasula (cuya voz es la que aparece en la película de Tocy quien también ilustra las secciones de la isla), mientras detrás de ellos se proyectaban imágenes en una pantalla (Gibbons, 2012). 
azules activan relatos escritos en rollos de pergamino (que también se presentan contenidos en una campana de cristal). Estos textos son una especie de parábolas o historias sobre personas del mundo de Efemera, quienes tratan de lidiar de distintas maneras con el desorden temporal de su mundo, o fragmentos de la historia de los orígenes de la máquina de influencia que causó este desorden. Las ranuras rojas de la pianola activan videos cortos, también reproducidos dentro de campanas, y las verdes despliegan coordenadas y distancias de soles de otros sistemas planetarios.

Los ocho videos de esta sección provienen de la instalación interactiva de la artista Zoe Beloff, realizada en el 2003: "La máquina de influenciar de la señorita Natalija A.”. Beloff se inspiró a su vez en el ensayo del psicoanalista vienés Victor Tausk "Sobre el origen esquizofrénico de la 'máquina de influenciar'”, que documenta el caso de un paciente que creía que un extraño aparato eléctrico operado por ingenieros en Berlín manipulaba sus pensamientos. Esta idea se extiende a todos los niveles narrativos de TOC.

Cuando se completan todos los nodos de esta pantalla de navegación, el lector/usuario puede avanzar a otra, después de ver una animación de transición. En este caso, la interfaz es la imagen de una isla, rodeada por 21 lunas que eclipsan al sol. Al hacer clic en cada una de ellas se maximiza un texto o una imagen. Las imágenes son pinturas de María Tomasula, la esposa del autor, y los textos son otro conjunto de parábolas o historias sobre los habitantes de la isla. Según N. Katherine Hayles, "[...] la isla explora la relación entre los regímenes temporales y el socius" (Hayles, 2012, p. 128). Jean-Yves Pellegrin describe esta pantalla de la siguiente manera:

[La] isla [está] dividida verticalmente, de izquierda a derecha, en tres áreas (anochecer, día y amanecer), y cada una corresponde a tres espacios diferentes habitados por tres tribus: los тос, a la izquierda, son personas orientadas hacia el pasado. Los TIC, a la derecha, se orientan hacia el futuro. En el centro de la isla, una raza híbrida de exiliados de ambas tribus vive exclusivamente en el presente (Pellegrin, 2010, p. 182).

Una vez que el espectador ha leído o abierto todos los nodos en esta pantalla, puede acceder a la animación del viaje final, que muestra la máquina de influencia y el corazón humano que la alimenta, y luego los créditos finales anuncian, como en una película, el final de la novela. 


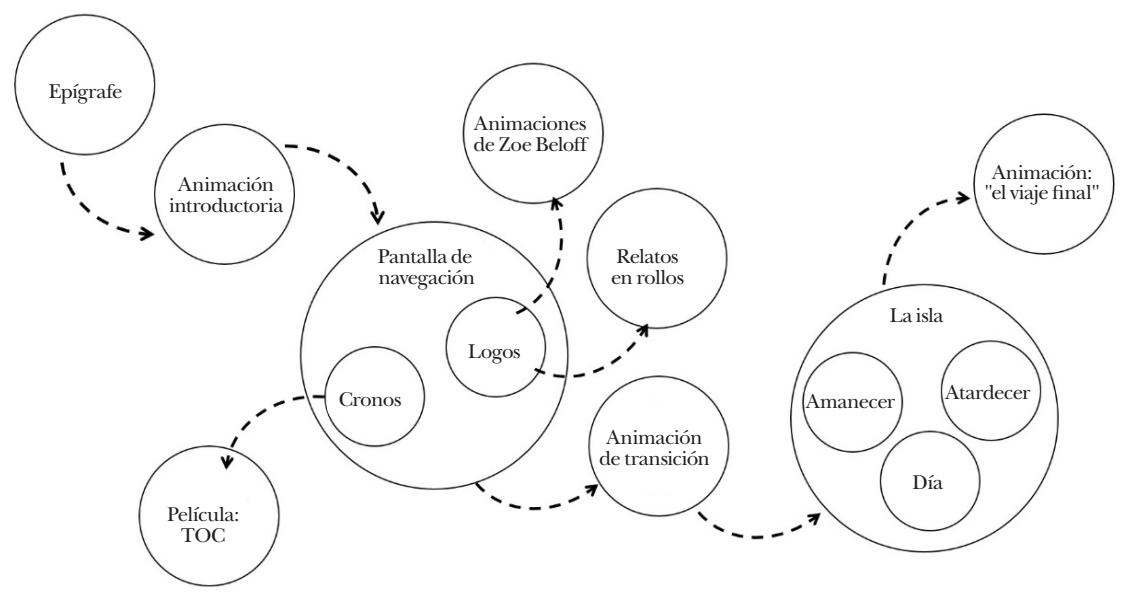

Figura 1. Estructura narrativa de Toc: A New Media Novel. Fuente: adaptado de Gibbons (2012)

Como podemos ver en esta presentación del diseño estructural de TOC, el tiempo se explora aquí a través de una serie de metáforas y descripciones que algunos autores han abordado desde perspectivas muy diferentes. Según Pellegrin, tras los personajes e historias de TOC subyace la concepción aristotélica de tiempo, que lo entiende como número, aquello que se puede contar. El tiempo aristotélico, asociado con el desplazamiento de los cuerpos en el espacio, es lineal:

De esta proposición se sigue una visión del tiempo abstracto del reloj como una secuencia lineal de intervalos que, a diferencia de los ciclos naturales, impone una dirección a los procesos que miden, colocándolos en lo que los físicos llaman "la flecha del tiempo". Esta noción se ejemplifica mejor mediante la segunda ley de la termodinámica, mencionada varias veces en (la película de) "Cronos" como el ineludible fíat del destino (Pellegrin, 2010, p. 179).

En cuanto a la historia de Logos, Pellegrin la asocia con la descripción lingüística del tiempo desarrollada por François Jullien, quien afirma: "[...] debido a que nuestras lenguas tienen conjugaciones, desde los griegos y los latinos distinguimos sistemáticamente y contrastamos el 'pasado', el 'futuro' y el 'presente”" (Pellegrin, 2010, p. 183). De ahí que el sistema de tiempos de la lengua también nos hace visualizar el tiempo como una línea que puede segmentarse en instancias separadas. En ese 
sentido, Cronos y Logos son las dos caras del mismo sistema: la cronología. No obstante, Pellegrin afirma que TOC logra transgredir esta lógica a través de los ritmos de lectura y visualización que ofrecen sus textos y películas, de manera que el espectador logra escapar a la cronología y entrar en una especie de “[...] navegación contemplativa” (Pellegrin, 2010, p. 189).

En su interpretación de las estrategias narrativas multimodales de TOC, Alison Gibbons también afirma que, desde la cita de San Agustín que sirve como epígrafe, la novela “[...] evoca contemplación” (Gibbons, 2012a). Así mismo, Gibbons identifica una serie de metáforas conceptuales empleadas por Tomasula en su representación del tiempo: el tiempo es espacio o el tiempo es movimiento hacia adelante, para mencionar solo dos de las más comunes en los usos cotidianos del lenguaje (Gibbons, 2012a).

Gibbons no desarrolla esta línea interpretativa, pues se concentra en la manera en que Tomasula y su equipo emplean la multimodalidad del medio digital para producir determinadas experiencias temporales en el usuario. Sin embargo, creo que la semántica cognitiva ofrece una serie de conceptualizaciones interesantes que permiten desarrollar esta idea, según la cual la estructura narrativa, la propuesta audiovisual y gráfica, y el diseño de interfaces de TOC revelan una compleja conceptualización del tiempo en nuestra época, que desarrollo a continuación.

\section{Metáforas y amalgamas: la conceptualización del tiempo}

La conceptualización metafórica del tiempo aparece con recurrencia en los estudios de la lingüística cognitiva. Diversos estudios de la teoría conceptual de la metáfora (TCM), han mostrado la presencia de metáforas espaciales para entender el tiempo diversas lenguas: desde las obras fundacionales de Lakoff y Johnson, en las cuales se analizan múltiples metáforas espacio-temporales (Johnson \& Lakoff, 2008, 2017) hasta trabajos consagrados específicamente a este tema, como los de Vyvyan Evans (2003) o Kevin Ezra Moore (2014), entre muchos otros.

Así mismo, la teoría de la integración conceptual (TIC) se ha ocupado de conceptualizaciones del tiempo en términos de redes de integración generalizadas. Ya en su principal obra, The Way We Think, Gilles Fauconnier y Mark Turner abordaban algunas de estas metáforas 
en términos de amalgamas o integraciones (Fauconnier \& Turner, 2002) ${ }^{3}$. En un trabajo posterior, Fauconnier y Turner proponen que las diferentes conceptualizaciones metafóricas del tiempo se pueden comprender desde la idea de redes de integración conceptual que pueden fusionar o combinar varias metáforas temporales en representaciones más complejas (Fauconnier \& Turner, 2008). Esta última propuesta provee el modelo que aplicaré aquí a algunos de los elementos que conforman la narrativa de TOC.

De acuerdo con Fauconnier y Turner, las distintas metáforas temporales "[...] se derivan de una red de integración sistemática pero elaborada que involucra un número de espacios de entrada (inputs), espacios integrados (blends), relaciones vitales y compresiones" (Fauconnier \& Turner, 2008, p. 56). Dentro de los inputs relevantes se encuentran:

Los eventos: los seres humanos suelen segmentar su experiencia vital en términos de eventos y objetos. En cuanto construcciones conceptuales, los eventos tienen unos límites espacio-temporales más o menos claros, e integran seres y objetos en líneas de acción. Los espacios mentales estructurados como eventos incluyen además la experiencia subjetiva de estos. Es decir, un mismo evento puede ser experimentado de distintas maneras por distintos sujetos y sus particulares puntos de vista. Los autores representan este tipo de espacios con la letra E.

Desplazamientos: un tipo particular de eventos para la cognición humana es el correspondiente al movimiento físico a través de un espacio, desde un punto A hasta un punto B, con sus correspondientes experiencias subjetivas. Fauconnier y Turner representan este tipo de eventos con la letra X. Los diversos desplazamientos son organizados según la lógica espacial.

La metáfora de la estructura de evento: es la fusión de los dos inputs anteriores: $\mathrm{E} / \mathrm{X}$, de manera que los eventos no espaciales pueden ser entendidos como desplazamientos espaciales, como en la expresión "este tema ya lo pasamos, ahora estamos en otro" o "ya estamos por llegar al final de la charla".

La amalgama del "ciclo": en su obra The Way We Think, Fauconnier y Turner identificaron un tipo muy común de integración conceptual que

3 Una presentación exhaustiva de estas dos teorías dominantes en el ámbito de la lingüística y la semántica cognitivas exigiría muchas páginas. Por eso recomiendo las dos obras aquí citadas, en las cuales aparecen sus formulaciones originales. Para una presentación sintética, pero completa y de gran claridad, puede consultarse la obra de Evans y Green (2006). 
denominaron el dominio integrado $M$, y que consiste en que, a partir de las similitudes entre los eventos que integran cada jornada de nuestra vida (el sol "sale", la luz cambia a lo largo del día según sus posiciones, luego se "oculta" y adviene la noche, etc.), los seres humanos integramos la multiplicidad de los días en un solo "día cíclico", denotado con la letra C. Este primer blend sirve como input para el dominio integrado $\mathrm{M}$, en una red en la que fusiona con otro mecanismo, natural o artificial, que provea una estructura perceptible para representar el ciclo de los días. Es el caso de los relojes analógicos, que proveen una superficie circular segmentada en doce unidades y unas manecillas que se desplazan con un eje central. Al fusionar el día cíclico con la estructura del reloj, aparece una estructura emergente, que ofrece unidades como segundos, minutos, horas, días, meses, etc., lo que da lugar a una sólida convención social que rige todos nuestros ritmos vitales y los eventos de nuestras vidas. No obstante, el dominio integrado $\mathrm{M}$ funciona con distintos tipos de mecanismos: relojes de arena, clepsidras, relojes digitales, relojes de sol y cualquier otro tipo de dispositivo que permita equiparar unidades espaciales en un ciclo con unidades temporales de una serie de eventos:

El cambio desde inicio hasta terminación define, por ejemplo, una "hora". Concebimos que todo en el universo pasa por esa hora. ¿Cómo nos relacionamos en la práctica con este evento universal idealizado? Nos relacionamos con él porque la compresión garantiza que cualquier evento local que involucre el movimiento de un reloj tolerablemente preciso (reloj mecánico, reloj de arena, sol) se asigna de manera consistente al evento idealizado universal" (Fauconnier \& Turner, 2008, p. 58).

Sin embargo, dentro de esta lógica, el dominio M no nos "provee" tiempo, sino que es un "sistema sofisticado de eventos emergentes universales", que denominamos minutos, horas, segundos. Una vez instaurado este tipo de eventos, emerge una nueva forma de integración conceptual, que fusiona a $\mathrm{E}, \mathrm{X}$ y $\mathrm{M}$.

Tiempo objetivo y experiencia subjetiva: la fusión de E/X con M da lugar a un espacio integrado donde los eventos universales de $\mathrm{M}$ se convierten en eventos locales de E/X. Así, el evento universal se convierte en una unidad universal de extensión espacial, es decir, una unidad de medida como los metros, las yardas, las pulgadas, etc. De ahí que cualquier evento tenga una extensión, medida en horas, minutos y demás unidades temporales, ahora concebidas como unidades espaciales. 
Pero otra posibilidad que se abre con esta integración es la de extender la percepción subjetiva de la extensión temporal a estos eventos universales que son las horas, los minutos y las demás unidades cronológicas. De esta manera, así como una conferencia puede ser interminable (como si la recorriéramos), una hora también lo puede ser, y esto varía de un sujeto a otro ${ }^{4}$ :

en $\mathrm{E} / \mathrm{X} / \mathrm{M}$, pasar una hora puede ser placentero para ti pero doloroso para mí, o rápido para ti pero lento para mí [...] esos eventos universales se vuelven eventos locales experimentados subjetivamente, de modo que pueden variar según la experiencia, no solo de sujetos distintos, sino también del mismo sujeto, según las circunstancias (Fauconnier \& Turner, 2008, p. 59).

Este último megablend puede desplegarse de diversas formas, privilegiando en unos casos el concepto de tiempo universal o en otros el de la percepción subjetiva del tiempo. La inclusión del punto de vista subjetivo también permite entender las unidades temporales como objetos en movimiento que se desplazan hacia el sujeto ("las horas pasan") o el ego como objeto que se desplaza hacia o a través del tiempo (véase nota 4). Así, Fauconnier y Turner nos revelan el trasfondo cognitivo de una de las convenciones más poderosas que ritman nuestra vida cotidiana. Pero toda convención puede ser destruida, como nos demuestra Steve Tomasula.

\section{La destrucción del reloj: deconstruyendo el tiempo universal}

Después de este breve recorrido por la semántica cognitiva (y valga aquí también la metáfora espacial) podemos regresar al universo enrarecido de

4 Es importante recordar que estas conceptualizaciones varían de una lengua a otra, de una cultura a otra: el ejemplo original de Fauconnier y Turner es: "go through a lecture", en el que es el oyente el que "atraviesa" o recorre una conferencia, mientras que en español, se diría más bien que la conferencia "pasó rápido" si fue agradable, o "pasó lento" si no fue de nuestro agrado. En todo caso, el modelo general se puede ajustar a las dos versiones, como se mostrará enseguida. En un estudio reciente que comparaba hablantes nativos de sueco y español (los sujetos del estudio hablaban los dos idiomas), Emanuel Bylund y Panos Athanasopoulos demostraron que conceptualizaban el tiempo de manera distinta: en sueco se privilegian las construcciones que lo describen en términos de extensión (tiempo largo, tiempo corto), mientras que en español, se conceptualizaba en términos de acumulación de cantidades: mucho tiempo, poco tiempo (Bylund \& Athanasopoulos, 2017). 
TOC. La idea que quiero proponer aquí es que la obra de Tomasula es una deconstrucción sistemática de la cascada de integraciones conceptuales o metáforas que Fauconnier y Turner presentan con tanta experticia y que, como apuntaba Pellegrin, estaba ya en la cronología aristotélica, pero se manifiesta sobre todo en los dispositivos tecnológicos que ritman nuestras existencia.

Lo interesante de la propuesta de Tomasula es que, sin salirse de esta línea cronológica, presente incluso en la estructura narrativa de su novela interactiva, logra producir el efecto de defragmentación y mosaico temporal que pregonan varios de sus personajes. Efectivamente, Toc es una narración lineal, aunque con bifurcaciones, que se le ofrecen al usuario como formas de multilinealidad. No obstante, a medida que se avanza en la "lectura" de las distintas líneas narrativas, la experiencia de la linealidad se va imponiendo, en un efecto que se exacerba cuando se recorre esta narrativa por segunda o tercera vez. Las etapas se vuelven engorrosas, pero no hay un elemento de la interfaz que le permita al usuario abandonar la línea de etapas que se le proponen. Este efecto de "angustia" temporal es particularmente álgido en la narrativa de Cronos, pues los elementos que se deben completar parecen interminables: aunque la lista de videos, textos y coordenadas es limitada, la combinación entre la irritante música de la pianola y la dificultad de acertar con la mirilla del cursor en cada uno de los orificios en movimiento producen el efecto de elongación del tiempo descrito por Fauconnier y Turner.

En ese sentido, lo que podría leerse como un error o dificultad en la navegabilidad de TOC (el hecho de que no se pueda entrar y salir de cualquier punto de su estructura, a la manera de un rizoma), se convierte en realidad en una cronología impuesta que fuerza la irritación psicológica del espectador.

Un efecto similar ocurre con los textos en rollos que se despliegan en las campanas de cristal. Tomasula escoge una interfaz particularmente difícil para la lectura de textos, que nos retrotrae a etapas pretéritas de la cultura escrita: los rollos de pergamino en lugar de los folios de los libros. Estos textos, además, están llenos de historias que subvierten la metáfora del tiempo trastocado en espacio: en ellos las personas pueden cavar túneles en la tierra que los conducen al pasado o al futuro; una mujer inventa un dispositivo para acumular el tiempo; alguien más desciende o asciende en líneas temporales en las que el futuro puede estar arriba o abajo, al igual que el pasado. En estas historias parece que, más que apelar a las metáforas del tiempo como espacio, se estuviera invirtiendo 
o desmembrando estas metáforas, a través del recurso del absurdo o de la paradoja.

Por otra parte, el mundo de TOC es tan paradójico en su apariencia y constitución espacial como lo son sus líneas temporales: parece a veces teñido del aura mítica de los relatos ancestrales, y, en otros momentos, se ofrece futurista e hipertecnológico. Muchas de las películas contenidas en este puzle audiovisual ofrecen imágenes de ciudades contemporáneas, mientras que otras animaciones nos conducen a islas primitivas donde una tecnología anacrónica se camufla entre la vegetación.

La última pantalla de navegación pareciera completar el cronopaisaje aristotélico, pero en realidad también lo cuestiona: las tribus TOC y TIC, antagonistas pero nunca realmente enfrentadas, tratan de anular ontológicamente a su oponente (se llaman mutuamente los "no gente"), mientras los híbridos del centro parecen no acabar de dibujarse en este último mosaico. Si el presente es un punto móvil que se desplaza entre protenciones y retenciones, los habitantes de ese punto son y no son, atrapados en la doble negación de los Tí y los TOC. Así, la onomatopeya del latido tecnológico parece solo admitir dos tiempos, irrealizando ese intervalo que podríamos llamar presente. Esta pantalla, estructurada en tres áreas en las que se distribuyen las fases de la luna, recoge el blend del ciclo, con su delimitación establecida por las apariciones y desapariciones del sol y de la luz.

Finalmente, el relato-marco de Efemera y sus dos hijos reúne esa gran red de integraciones que proponen Fauconnier y Turner, añadiendo otro nivel que estos dos autores no describieron: se trata de esa gran metáfora conceptual que es el huso horario: ese telar del tiempo que se dibuja sobre el mapa esférico de la tierra, distribuyendo las zonas horarias según los meridianos, para coordinar el movimiento giratorio de la tierra con las máquinas encargadas de cuantificar sus tiempos. Así, el huso horario es la megamáquina creada por nuestra especie para coordinar a todos los otros dispositivos temporales y unificar ese tiempo universal coordinado de los relojes y los calendarios. De ahí surge el conflicto entre Cronos y Logos por la primacía sobre el reino de Efemera, el instante, la madre de toda temporalidad, creadora de la máquina de influencia, un gran dispositivo que trastoca todos los tiempos y sus mediciones. En este mundo se puede aventurar la idea de que esta máquina es justo lo opuesto: alimentada por los latidos del corazón humano, en lugar de inducir comportamientos en las personas a través de proyectar alucinaciones a distancia, esta máquina lo que hace es retirar el velo de la ilusión temporal, según el 
cual el tiempo universal de los relojes es el propio tiempo cósmico de las constantes científicas.

En la última película, la que se activa después de recorrer las lunas suspendidas sobre la isla, hay un efecto de zoom out en el que el punto de vista se va alejando de la isla, del continente, del planeta, y revela que la tierra es una pieza de engranaje en un mecanismo mayor, el sistema solar, el cual, a su vez, se empequeñece, revelándose como una especie de reloj suspendido en el espacio, donde otras máquinas planetarias completan sus ciclos repetitivos, y finalmente desaparecen en un cosmos plagado de estrellas, un universo que continúa en expansión como el tic de un latido que se contraerá en un toc, hasta su propio colapso.

Así, la gran máquina de influencia es la propia novela $T O C$, que termina alterando ese tiempo cronométrico que todos los dispositivos que nos rodean no dejan de marcar. Pues todas las máquinas son máquinas del tiempo.

\section{Conclusión}

Como objeto tecnológico, TOC está sujeto a los deterioros y caducidades propias de su medio. No obstante, como máquina narrativa rebasa esas limitaciones y continúa interpelando la manera en que pensamos la relación entre tecnología y temporalidad. En el epígrafe de este texto, Tomasula reflexiona en torno a la pertinencia de ciertas formas (narrativas, estéticas) para captar su contemporaneidad, y se pregunta si la forma-novela todavía puede hablarle al presente. En otro pasaje de la misma entrevista, sin embargo, el autor cuenta por qué escogió esta forma de expresión:

Una razón por la que me gusta trabajar en la forma-novela es que es lo suficientemente holgada como para incluir cualquier cosa (cartas, informes, poemas), así que, ¿por qué no incluir también música y animación? La novela se presta de forma natural para una estética de collage, o a cierto tipo de mentalidad de apropiación, el tipo corta-pegaarde que alienta todas las artes, toda la cultura actual. De modo que sí, TOC es literatura, ya que conserva la lectura y el lenguaje como su medio, y es un libro, incluso si tienes que leer Toc en un iPad (Banash \& Tomasula, 2015, p. 174). 
Una de las posibilidades que se abren para ToC al incluir el medio audiovisual y la interactividad es que muchas de las ideas que expresa en su contenido sobre el tiempo, el espacio, el movimiento y la posibilidad de fusionarlos y combinarlos de múltiples formas se materializan también en las acciones y elecciones que le ofrece al usuario. No obstante, Tomasula es coherente con su idea de que TOC es, por encima de todo, un relato verbal: incluso sus películas y animaciones tienen siempre alguna forma de narración, diversas voces que cuentan historias, en algunos casos a la manera de los antiguos bardos, en otras más según esa estética de collage y superposición de audios distorsionados.

Es a través de palabras que se expresa esa red de metáforas espaciotemporales que luego se desestructuran, a partir de la figura retórica de la paradoja. Es a este nivel en el que el trabajo sobre las metáforas de la vida cotidiana que hacen evidente nuestra manera de conceptualizar el tiempo, y que tienen su equivalencia en los dispositivos tecnológicos que lo cuantifican, miden y disponen en esa interfaz omnipresente del "tiempo universal”, se vuelve más incisivo.

Uno de los textos de Logos se titula, precisamente, "La estructura del tiempo", y describe al tiempo como una inmensa torre de cartas, sostenidas por pura inercia, cada una de las cuales es una capa narrativa, una historia subsidiaria de aquella en la que se apoya. En la punta de la torre hay un átomo con sus electrones vibrando en silencio, pues su movimiento es tan rápido que el sonido que producen es imperceptible. Debajo de esta se encuentra una capa constituida por moléculas, que son como "motores microscópicos o cosmos", sostenida sobre una capa de relojes atómicos. La siguiente es de relojes digitales, apoyados sobre un estrato de relojes mecánicos, y, más abajo, como se puede adivinar, hay un bloque de relojes de sol y velas. Por debajo de esta capa se encuentra la tierra, atascada en una gran marea de planetas que se expanden y contraen en torno a la torre como un animal agonizante.

Esta es la última capa visible, pues la torre se hunde en el mar, allí donde se encuentra la verdadera base de la torre: "[...] la única capa que estaba en reposo, la única capa contra la cual se medía cualquier cambio y que, por lo tanto, estaba más allá de la influencia de cualquier máquina, sin importar qué tipo de corazón poseyera; es decir, el estrato que hacía posible todo tiempo: la fría, infinita inmensidad del espacio en sí” (Tomasula, 2009). 
Esta imagen de la torre parece replicar, de manera invertida, la cascada de integraciones conceptuales construida con la misma laboriosidad por Fauconnier y Turner, para mostrarnos la complejidad de la trama que sostiene nuestros ritmos cotidianos: atrapados entre Cronos y Logos, el tiempo de la ciencia y la tecnología, y el tiempo del lenguaje, un tiempo sostenido en el espacio, cuantificable y discreto, que Tomasula nos ayuda a desarmar.

\section{Referencias}

Banash, D. (2015). Steve Tomasula. The Art and Science of New Media Fiction. New York/London: Bloomsbury.

Banash, D., \& Spain, A. (2015). Introduction: Composition, Emergence, Sensation: Science and New Media in the Novels of Steve Tomasula. En D. Banash, Steve Tomasula. The Art and Science of New Media Fiction (pp. 1-24). New York/ London: Bloomsbury.

Banash, D., \& Tomasula, S. (2015). Afterword. An Interview with Steve Tomasula.

En D. Banash, Steve Tomasula. The Art and Science of New Media Fiction (pp. 285304). New York/London: Bloomsbury.

Berens, K. I. (2015). Touch and Decay: Tomasula's Toc on ipad. En D. Banash, Steve Tomasula. The Art and Science of New Media Fiction (pp. 167-182). New York/ London: Bloomsbury.

Boroditsky, L. (2000). Metaphoric structuring: understanding time through spatial metaphors. Cognition, 1-28.

Bray, J., Gibbons, A., \& McHale, B. (2012). The Routledge Companion to Experimental Literature. New York: Routledge.

Bylund, E., \& Athanasopoulos, P. (2017). The Whorfian Time Warp: Representing Duration Through the Language Hourglass. Journal of Experimental Psychology: General, 146(7), 911-916.

Conde, J. A. (2011). Límites y posibilidades de la novela hipermedia. Memorias digitales del VIII Foro de Diseño/Festival de la Imagen (CD ROM). Manizales: Universidad de Caldas.

Evans, V. (2003). The Structure of Time. Language, meaning and temporal cognition. Amsterdam/Philadelphia: John Benjamins Publishing Company.

Evans, V., \& Green, M. (2006). Cognitive Linguistics. An Introduction. Edinburgh: Edinburgh University Press.

Fauconnier, G. (1994). Mental Spaces. Aspects of Meaning construction in Natural Language. Cambridge: Cambridge University Press.

Fauconnier, G., \& Turner, M. (2002). The Way we Think. Conceptual Blending and the Mind's Hidden Complexities. New York: Basic Books.

Fauconnier, G., \& Turner, M. (2008). Rethinking Metaphor. En J. R. Gibbs, The Cambridge Handbook of Metaphor and Thought (pp. 53-66). Cambridge/New York: Cambridge University Press. 
Gentner, D., Imai, M., \& Boroditsky, L. (2002). As time goes by: Evidence for two systems in processing space-time metaphors. Language and Cognitive Processes, 537-565.

Gibbons, A. (2012, 28 de junio). Electronic Book Review. Retrieved from "You've never experienced a novel like this": Time and Interaction when reading TOC: http://www.electronicbookreview.com/thread/fictionspresent/linear

Gibbons, A. (2012). Multimodality, Cognition, and Experimental Literature. New York: Routledge.

Hayles, N. K. (2004). Print Is Flat, Code Is Deep: The Importance of MediaSpecific Analysis. Poetics Today, 67-90.

Hayles, N. K. (2012). How we Think: Digital Media and Contemporary Technogenesis. Chicago: The University of Chicago Press.

Hurault-Paupe, A. (2015). Intermediality in Steve Tomasula's Toc: A New Media Novel: A Semiological Analysis. En D. Banash, Steve Tomasula. The Art and Science of New Media Fiction (pp. 183-208). New York/London: Bloomsbury.

Inman Berens, K. (2015). Touch and Decay: Tomasula's ToC on iPad. En D. Banash, Steve Tomasula: The Art and Science of New Media Fiction (pp. 167-182). New York and London: Bloomsbury.

Johnson, M., \& Lakoff, G. (2008). Philosophy In The Flesh. The Embodied Mind and its Challenge to Western Thought. New York: Basic Books.

Johnson, M., \& Lakoff, G. (2017). Metáforas de la vida cotidiana. Madrid: Cátedra.

Moore, K. E. (2014). The Spatial Language of Time. Metaphor, metonymy, and frames of reference. Amsterdam/Philadelphia: John Benjamins Publishing Company.

Núñez, R. E., \& Sweetser, E. (2006). With the Future Behind Them: Convergent Evidence From Aymara Language and Gesture in the Crosslinguistic Comparison of Spatial Construals of Time. Cognitive Science, 401-450.

Núñez, R. E., Motz, B. A., \& Teuscher, U. (2006). Time After Time: The Psychological Reality of the Ego- and Time-Reference-Point Distinction in Metaphorical Construals of Time. Metaphor and Symbol, 133-146.

Olsen, L. (2015). Ontological Metalepses, Unnatural Narratology, and Locality: A politics of the [[ Page ]] in Tomasula's VAS $\mathcal{E}^{2}$ TOC. En D. Banash, Steve Tomasula. The Art and Science of New Media Fiction (pp. 209-224). New York/ London: Bloomsbury.

Page, R. (2010). New Perspectives on Narrative and Multimodality. New York/London: Routledge.

Pellegrin, J.-Y. (2010). Tactics Against Tic-Toc: Browsing Steve Tomasula's New. Études anglaises, 174-190.

Tomasula, S. (2009). Toc: A New Media Novel. Tuscaloosa: The University of Alabama Press.

Tomasula, S. (2012). Code Poetry and New-media Literature. En J. Bray, A. Gibbons, \& B. McHale, The Routledge Companion to Experimental Literature (pp. 483-496). New York: Routledge.

Tomasula, S. (2012). Information Design, Emergent Culture and Experimental Form in the Novel. En J. Bray, A. Gibbons, \& B. McHale (eds.), The Routledge Companion to Experimental Literature (pp. 435-451). New York: Routledge. 